\title{
How does social competition affect true and false recognition?
}

\author{
Zhenliang $\mathrm{Liu}^{1,2} \cdot$ Tiantian Liu $^{1} \cdot$ Yansong $\mathrm{Li}^{1,2}$
}

Accepted: 30 August 2020 / Published online: 15 September 2020

(C) The Psychonomic Society, Inc. 2020

\begin{abstract}
Memory is highly susceptible to distortions, which can exert serious consequences in daily life. Despite this, we still know little about the role of factors that comprise social contexts in which memory processes occur. In the present study, we attempted to address this issue by examining how social competition influences true and false recognition. Participants performed a version of the Deese-Roediger-McDermott (DRM) paradigm designed to lure them into producing both true and false recognition either in competition against or independently of another person. We found that participants in the competition group showed lower levels of true and false recognition than those in the control group. Signal-detection analyses revealed that participants in both groups showed equivalent memory sensitivity for true recognition, while those in the competition group exhibited a decreased sensitivity for false recognition, which implies enhanced item-specific encoding during social competition. Moreover, participants in the competition group showed a more conservative response bias for both true and false recognition at retrieval than those in the control group, indicating a shift towards conservatism in decision strategy for both true and false recognition during social competition. The results provide compelling evidence for a decision-based reduction of true recognition and both encoding-based and decision-based reductions of false recognition under competitive contexts. Therefore, these novel findings may have implications both for understanding the powerful role of social competition on true and false memories and for understanding the potential role of social competition on other aspects of memory processes.
\end{abstract}

Keywords Social competition $\cdot$ False memory $\cdot$ Sensitivity $\cdot$ Response bias

\section{Introduction}

In our daily life, memory processes can be prone to distortions and illusions in the form of false memory (Brainerd \& Reyna, 2005; Gallo, 2013; Loftus \& Pickrell, 1995; Roediger \& Mcdermott, 1996; Schacter, Guerin, \& Jacques, 2011). Given such a phenomenon of high prevalence, considerable efforts have been dedicated in recent decades to empirically exploring how memory processes are distorted by a variety of factors. In addition to factors associated with features intrinsic to memory tasks, the available literature suggests that memory processes are sensitive to social contexts in which memory processes occur (Barnier, Sutton, Harris, \& Wilson, 2008;

Yansong Li

yansongli@nju.edu.cn

1 Reward, Competition and Social Neuroscience Lab, Department of Psychology, School of Social and Behavioral Sciences, Nanjing University, Nanjing 210023, China

2 Institute for Brain Sciences, Nanjing University, Nanjing 210023, China
Bless, Strack, \& Walther, 2001; Bookbinder \& Brainerd, 2016; Echterhoff \& Hirst, 2009; Newbury \& Monaghan, 2019; Weldon, 2000; Wyer \& Srull, 1986), even though substantially less research has focused on addressing this issue.

Prior studies have revealed that factors such as implicit social pressure (Reysen, 2007), memories of social interaction (Straube, Green, Chatterjee, \& Kircher, 2011), and confirmatory feedback on confabulated responses (Zaragoza, Payment, Ackil, Drivdahl, \& Beck, 2001) can promote the development of false memories. Conversely, a variety of factors have consistently been proven to be effective at reducing false recognition. These include provision of explicit warnings prior to testing about the effect of false memory (Carmichael \& Gutchess, 2016; Gallo, Roberts, \& Seamon, 1997; Mccabe \& Smith, 2002; Mcdermott \& Roediger, 1998; Watson, Mcdermott, \& Balota, 2004), higher levels of post-learning arousal (Nielson \& Correro, 2017; Nitschke, Chu, Pruessner, Bartz, \& Sheldon, 2019), social stress experienced before learning or at retrieval (Diekelmann, Wilhelm, Wagner, \& Born, 2011; Pardilla-Delgado, Alger, Cunningham, Kinealy, \& Payne, 2015; Smeets, Otgaar, Candel, \& Wolf, 2008; 
Zoladz et al., 2014), and induced negative affect (Forgas, Laham, \& Vargas, 2015; Storbeck, 2013; Storbeck \& Clore, 2005, 2011). Moreover, social collaboration has also been shown to be capable of improving recall and recognition (Rajaram \& Pereira-Pasarin, 2007; Weldon \& Bellinger, 1997). Taken together, these studies illustrate the powerful role of socio-motivational factors in shaping memory processes. Clearly, the social factors that influence memory outlined here are limited and highlight a need to further advance our knowledge of contextual modulation on memory by exploring the potential influence that arises from other social circumstances.

Social competition is an important and universal form of social influence that arises in competitive contexts (Casto \& Edwards, 2016; Deutsch, 1949; Johnson \& Johnson, 1989; Murayama \& Elliot, 2012). It is an elementary and universal form of social interaction in that it is basic to all other forms of social interaction and it can take many forms in our daily life, such as job promotion within a working environment or performance in a sport. Moreover, in some cases such as the World Memory Championships and College Entrance Examination, individuals' higher performance depends largely on the extent to which they can efficiently learn and memorize study materials during competitive interactions with opponents. Given such considerations, the importance of understanding the role of social competition on memory as a focus of experimental inquiry is clear. Surprisingly, the effects of social competition on memory processes have not been studied systematically until recently (D'Angelo, Bosco, Bianco, \& Brandimonte, 2012; Dimenichi \& Tricomi, 2015, 2017; Ngaosuvan \& Mäntylä, 2010). This preliminary evidence suggests that social competition yields powerful effects on memory processes.

Despite such evidence, there has still been a lack of empirical research investigating memory distortions in the context of social competition. In the present study, we attempted to address this question by examining whether and how social competition affects true and false recognition. To this end, participants were required to complete a version of the Deese-Roediger-McDermott (DRM) paradigm (Deese, 1959; Roediger \& McDermott, 1995) whereby individuals can be lured into producing both true and false recognition in competition against or independently of another person. The DRM paradigm is widely considered a reliable "false-memory" paradigm and has been demonstrated to be a convenient means of studying true and false recognition in the laboratory (Blair, Lenton, \& Hastie, 2002; Pardilla-Delgado \& Payne, 2017a). In this paradigm, participants were presented with word lists composed of associates that converge on non-presented critical words at encoding. After a delay, they were asked to complete a recognition test containing three types of test items: targets, related distractors, and unrelated distractors.
In false-memory research, there is increasing evidence that demonstrates that the way in which study materials are encoded can modulate recognition performance (Arndt \& Reder, 2003; Hege \& Dodson, 2004). With regard to encoding processes, two major types can typically be distinguished: (a) item-specific processing and (b) relational processing (Anderson, 1972; Hunt \& Einstein, 1981; Hunt \& Mcdaniel, 1993). Item-specific processing involves the encoding of items by their individual elements, distinctive qualities, and features from which verbatim representations are formed. Relational processing, on the other hand, is concerned with the encoding of relationships among elements and producing gist representations. According to the activation-monitoring framework (Gallo, 2010; Roediger \& Mcdermott, 2000; Roediger, Watson, Mcdermott, \& Gallo, 2001) or the fuzzytrace theory (Brainerd \& Reyna, 1998; Brainerd, Wright, Reyna, \& Payne, 2002; Reyna \& Brainerd, 1995), these two factors contribute to recognition performance. Given that achieving the goal of winning against an opponent depends on whether participants attain a higher recognition performance than their opponents in the context of social competition (Johnson \& Johnson, 1989), one can expect that social competition affects recognition performance possibly through its modulation on how study materials are encoded. Specifically, the activation-monitoring framework proposes that activation processes generally arise from encoding circumstances that activate representations of related distractors, such that lower levels of activation lead to subsequent lower rates of false recognition (Gallo, 2010; Roediger \& Mcdermott, 2000; Roediger et al., 2001). Social competition has been demonstrated to be a powerful means of promoting individuals' interest in study materials during learning (Plass et al., 2013) and directing their attentional focuses towards distinctive details of study materials during encoding (Dimenichi \& Tricomi, 2015; Hidi \& Renninger, 2006). Considering that a shift of attention towards distinctive details of study materials has been found to enhance item-specific processing during learning (Hege \& Dodson, 2004), within a social competition context one can expect that participants guide their attention to distinctive details of study materials rather than to relational information at encoding, thereby enhancing item-specific processing and reducing the activation of semantic associates. Given that item-specific processing and relational processing work in opposition to produce false recognition (Arndt \& Reder, 2003; Hege \& Dodson, 2004; Roediger et al., 2001), one could predict that item-specific processing encouraged by social competition during encoding would in turn lead to false recognition reduction.

A similar prediction could also be made based on the fuzzy-trace theory (Brainerd \& Reyna, 1998; Brainerd et al., 2002; Reyna \& Brainerd, 1995). This theory contends that two main types of memory trace are stored in parallel (Brainerd \& Reyna, 1998; Brainerd et al., 2002; Reyna \& 
Brainerd, 1995). Verbatim traces correspond to memory traces for individual items and represent specific attributes, whereas gist traces capture the general semantic meaning of experience, but without specific attributes (in the present case, of the lists). From this, one can expect that social competition during learning would favor the development of verbatim traces over that of gist traces. Given that gist and verbatim traces work in opposition to produce false recognition (Brainerd, Reyna, Ron, \& Mojardin, 2003; Reyna, Corbin, Weldon, \& Brainerd, 2016), enhanced verbatim-based processing may reduce the accessibility of gist traces during retrieval, resulting in a corresponding reduction in false recognition.

Furthermore, these two theories posit that either activation processes occurring during encoding or both gist and verbatim traces that are formed during encoding do not work in isolation and instead interact with additional control and decision processes that generally occur during memory retrieval, for instance criterion-setting or response bias (Benjamin, 2007; Curran, Debuse, \& Leynes, 2007; Kapucu, Rotello, Ready, \& Seidl, 2008; Paige, Amado, \& Gutchess, 2017; Verde \& Rotello, 2007). Considering the cost of errors under competitive contexts, participants may show a shift towards conservatism in decision strategy as the optimal decision criterion to minimize the likelihood of false recognition. Simultaneously, participants may also resort to a tightening response bias in response to a probe that does not produce clear retrieval of target memories or leads to retrieval of gist trace of similar targets to maximize their correct responding, thereby increasing the likelihood of mistakenly judging uncertain targets as items that were not seen at encoding and resulting in a corresponding true recognition reduction.

\section{Method}

\section{Participants}

To ensure adequate power, we determined the sample size by performing a power analysis using $\mathrm{G}^{*}$ Power Version 3.1 (Faul, Erdfelder, Lang, \& Buchner, 2007). We calculated that, at an alpha level of 0.05 and $80 \%$ power, the sample size needed to achieve a medium effect size (Cohen's $f=0.25$; Cohen, 1988, 1992) for our experimental design was at least 27 participants per condition. The assumption of a mediumsize effect was based on previous research investigating the influence of social competition on memory processes (Balas \& Thomas, 2015; Dimenichi \& Tricomi, 2015). In reality, we recruited 41 participants per condition in order to ensure robustness of the present study. Thus, a total of 82 right-handed adults (38 males, $M_{\text {age }}=20.95$ years, $S D=1.95$ ), recruited from the University of Nanjing psychology participant pool, completed the study. In addition to receiving a payment of 10 for taking part in the experiment, we also offered a bonus payment based on participants' performance and choices during the experiment that they would receive in cash at the end of the study. All participants had normal or corrected-tonormal vision and were naive with regard to the purpose of the experiment. All participants gave written informed consent prior to participation. This study was approved by the Nanjing University Institutional Review Board. In the present study, we report all measures, manipulations, and exclusions.

\section{Procedure}

\section{Pre-competition measures}

This experiment was conducted in the Experimental Laboratory at the Department of Psychology, University of Nanjing. At the start of the study, we administered several questionnaires to control for potential individual differences and how they might relate to task performance. We employed the Chinese version of the Cooperative and Competitive Orientation Scale (C-CCO) to assess how inclined participants were to compete (Chen, Xie, \& Chang, 2011). Gambling and social investment risk-taking among participants was assessed through the Chinese version of the Domain-Specific RiskTaking Scale (C-DOSPERT) (Hu \& Xie, 2012).

\section{The Deese-Roediger-McDermott (DRM) paradigm}

We used a version of the DRM paradigm to measure both true and false recognition (Deese, 1959; Roediger \& McDermott, 1995). Specifically, the task consists of three phases: a study phase, a distractor phase, and a test phase. During the study phase, participants were asked to study ten lists of 15 related words that were associates of a common word (called a related distractor) that was not presented in the list. The lists used in the present study were taken from a previous study (Stadler, Roediger, \& Mcdermott, 1999). These words were consecutively presented in the center position of the computer screen at a rate of one word every $2 \mathrm{~s}$. Immediately after the study phase, participants performed the distractor phase of the research session. This was involved in 5-min buffer activities in which participants were required to solve simple arithmetic problems (e.g., $3 \times 4+5=$ ?). Following the distractor phase, participants then performed the test phase. During the test phase, we administered a recognition memory test. The test list consisted of words belonging to three types of test items: 30 targets (i.e., old items from the study list), 10 related distractors, and 20 unrelated distractors that were not present in any of the previously studied lists. This 60 -item test list was presented at a rate of one word every $2 \mathrm{~s}$ in random order. Participants were asked to respond "yes" or "no" to each item. Immediately following the "old"/"new" classification, participants had to rate their decision confidence on a 9-point scale 
ranging from "very unsure" to "very sure" by pressing the corresponding number key on the keyboard.

\section{The competition manipulation}

The experimental protocol concerning the social competition manipulation was based on our previous studies focusing on group-based competition (Zhu, Guan, \& Li, 2015; Zhu, Wang, Lv, \& Li, 2016). Here, competition was manipulated between participants rather than groups. All participants were randomly assigned to two conditions (a competition group and a control group).

In the competition condition, participants were led to believe that they were competing against an opponent on the DRM paradigm via two linked computers. To further intensify the contest, they were informed that if their performance in the task was better than the opponent, they would receive the bonus payment of 10 . Otherwise, they would only receive the standard payment for participating in the experiment. In contrast, the control condition was identical to the competition condition, except that participants were told that they and another person would complete the DRM paradigm independently and they would not compete against each other. As such, no competition occurred between participants. They were asked to perform the task as well as possible and, if their performance fell above a predetermined criterion, they would receive the bonus payment of 10. Otherwise, they would only receive the standard payment for participating in the experiment.

To verify that the competition manipulation was effective, at completion of the memory task, participants were asked to provide a self-reported rating of perceived competition on a 9-point Likert scale ranging from 1 (not at all) to 9 (extremely).

\section{Results}

\section{Pre-competition measures}

Competitive orientation and risk-taking scores were analyzed using an independent-samples $t$-test. We did not find any significant difference in risk-taking between the competition group and the control group (Gambling: $t(80)=-0.16, p=$ 0.875; Social-investment: $t(80)=-1.18, p=0.241)$. In contrast, we observed a small but significant difference in competitive orientation between groups $(t(80)=$ $2.05, p=0.043$, Cohen's $d=-0.46)$. In order to control for any potential effects arising from such a betweengroup difference in the inclination to compete, we included this factor in subsequent analyses as a covariate.

\section{Competition manipulation check}

As a manipulation check, subjective ratings of perceived competition were analyzed using a one-way analysis of covariance (ANCOVA) with group (competition vs. control) as a between-subject factor and competitive orientation as a covariate. This analysis revealed a significant difference in such ratings between groups $\left(F(1,79)=19.41, p<0.001, \eta^{2}{ }_{p}=\right.$ $0.20)$. Specifically, participants in the competition group reported significantly greater levels of perceived competition $(M$ $=4.95, S E=0.28)$ than those reported by the control group $(M$ $=3.19, S E=0.28$ ), which clearly demonstrates that our competition manipulation was effective.

\section{Effects of social competition on recognition responses and confidence judgments}

To explore competitive modulation on recognition responses, the mean proportion of old responses was analyzed using a two-way mixed ANCOVA with group (competition vs. control) as a between-subject factor, test item type (targets vs. related distractors vs. unrelated distractors) as a withinsubject factor, and competitive orientation as a covariate. This analysis revealed that the main effect of group was significant $\left(F(1,79)=9.96, p=0.002, \eta_{p}^{2}=0.11\right)$. Participants in the competition group showed a decrease in recognizing items as "old" $(M=0.45, S E=0.02)$ compared with those in the control group $(M=0.52, S E=0.02)$. The main effect of test item type was also significant $(F(2,158)=19.225, p<0.001$, $\left.\eta_{p}^{2}=0.20\right)$. Bonferroni post hoc testing revealed that hit rates for targets were higher $(M=0.74, S E=0.01)$ than both related false alarms $(M=0.65, S E=0.02, p<0.001)$ and unrelated false alarms $(M=0.08, S E=0.01, p<0.001)$. It also revealed that related false alarms were higher compared to unrelated false alarms $(p<0.001)$ (Fig. 1). These main effects were further qualified by a significant interaction $(F(2,158)=$ 4.81, $p=0.009, \eta_{p}^{2}=0.06$ ) (Fig. 1). An analysis of simple effects revealed that hit rates for targets and related false alarms were significantly lower in the competition group than in the control group (targets: $F(1,79)=4.65, p=0.034, \eta_{p}^{2}=$ 0.06 ; related distractors: $F(1,79)=10.05, p=0.002, \eta_{p}^{2}=$ $0.11)$. However, unrelated false alarms did not differ significantly between groups $\left(F(1,79)=0.63, p=0.431, \eta_{p}^{2}=\right.$ $0.01)$. These results suggest that social competition reduces both hit rates for targets and false alarms to related distractors.

To further investigate the potential relationship between true and false recognition, in accordance with prior work using the DRM paradigms (Ballard, Gallo, \& Wit, 2012; Kim \& Cabeza, 2007; Pardilla-Delgado \& Payne, 2017b; Payne, Schacter, Propper, Huang, \& Stickgold, 2009), we performed correlation analyses between hit rates for targets and false alarms to related distractors in the control and competition groups, respectively. The results revealed a significant 


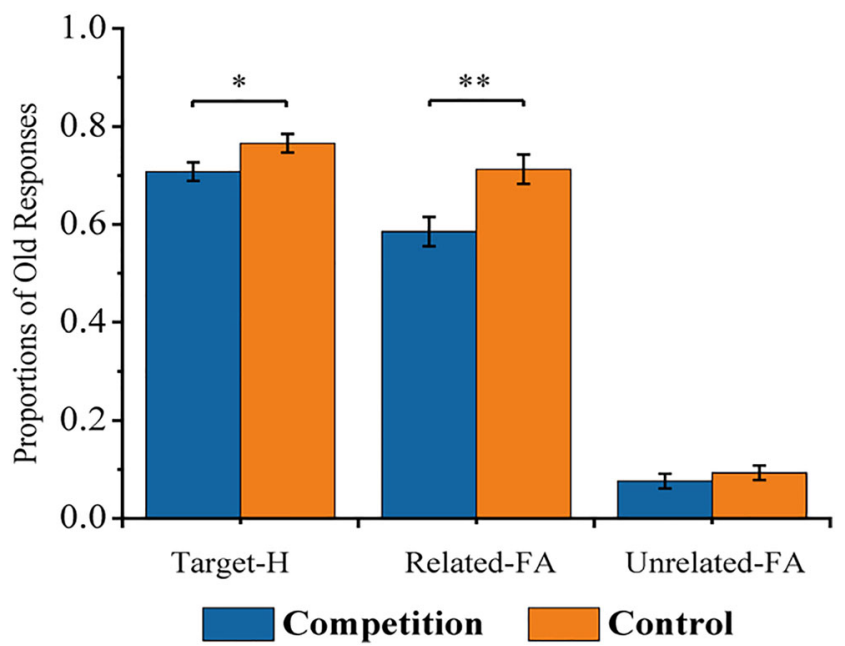

Fig. 1 Effects of social competition on recognition responses. Proportions of old responses as a function of group and test item type. Hit rates for targets and false alarms to related distractors were significantly lower in the competition group than in the control group. Error bars represent standard errors of the mean. Target- $H$, hit rates for targets, Related-FA, related false alarms, Unrelated-FA, unrelated false alarms. $* p<0.05, * * p<0.01$

correlation between hit rates for targets and false alarms to related distractors in the control group $(r=0.35, p=0.026)$ (Fig. 2A), but not in the competition group $(r=0.24, p=$ 0.128) (Fig. 2B).

To explore effects of social competition on confidence judgments, we performed a two-way mixed ANCOVA on confidence ratings with group (competition vs. control) as a between-subject factor, test item type (targets vs. related distractors vs. unrelated distractors) as a within-subject factor, and competitive orientation as a covariate. This analysis yielded no main effects of group $(F(1,79)=0.02, p=$ $\left.0.879, \eta_{p}^{2}<0.01\right)$, test item type $(F(2,158)=1.01, p=$ $\left.0.365, \eta_{p}^{2}=0.01\right)$, and no interaction between them $(F(2$, $\left.158)=1.07, p=0.345, \eta_{p}^{2}=0.01\right)$.

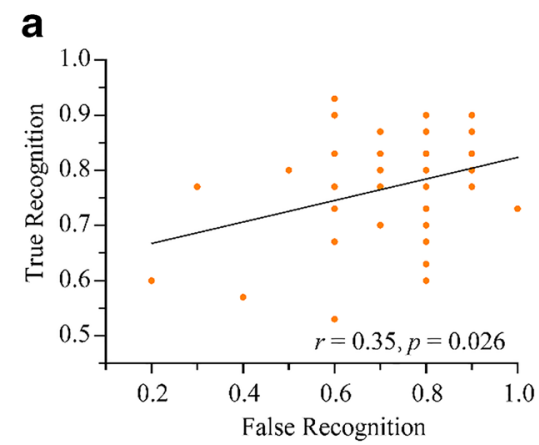

\section{Effects of social competition on signal detection measures of recognition memory}

In false-memory research, there has been increasing interest in reporting memory sensitivity $\left(d^{\prime}\right)$ and response bias $(C)$ for both true and false recognition in the DRM paradigm (Brainerd, Stein, Silveira, Rohenkohl, \& Reyna, 2008b; Pardilla-Delgado et al., 2015; Pesta, Murphy, \& Sanders, 2001; Seamon, Lee, et al., 2002a; Seamon, Luo, et al., 2002b; Storbeck \& Clore, 2011; Zheng, Lang, Wang, Xiao, $\& \mathrm{Li}, 2018)$. The signal detection measures of recognition memory can separate mnemonic from decision components and thus help with clarifying how encoding-related and decision-related processes underlying true and false recognition covaried with social competition in the present study. In accordance with these prior studies, a typical way to calculate the sensitivity $\left(d^{\prime}\right)$ and response bias $(C)$ measures for true recognition can be expressed as: $d^{\prime}=\mathrm{Z}_{\mathrm{H} \text { (targets) }}-\mathrm{Z}_{\mathrm{FA} \text { (unrelated }}$ distractors) and $C=-0.5 \times\left(Z_{\mathrm{H} \text { (targets) }}+\mathrm{Z}_{\mathrm{FA} \text { (unrelated distractors) }}\right)$, while those for false recognition can be estimated with the following equations: $d^{\prime}=\mathrm{Z}_{\mathrm{FA} \text { (related distractors) }}-\mathrm{Z}_{\mathrm{FA} \text { (unrelated }}$ distractors) and $C=-0.5 \times\left(Z_{\mathrm{FA}(\text { related distractors })}+\mathrm{Z}_{\mathrm{FA} \text { (unrelated }}\right.$ distractors) $)$.

To examine the effects of social competition on the $d^{\prime}$ and $C$ measures for true recognition, we performed two separate one-way ANCOVAs with group (competition vs. control) as a between-subject factor and competitive orientation as a covariate. The ANCOVA on the $d^{\prime}$ revealed no significant main effect of group $\left(F(1,79)=0.30, p=0.585, \eta_{p}^{2} 0.01\right)$ (Fig. $3 \mathrm{~A})$, reflecting equivalent memory sensitivity for true recognition across both groups. In contrast, the ANCOVA on the $C$ revealed a marginally significant main effect of group $(F(1$, $\left.79)=3.66, p=0.060, \eta_{p}^{2}=0.04\right)$. Participants in the competition group $(M=0.47, S E=0.05)$ showed a slightly more conservative response bias for true recognition than those in the control group $(M=0.33, S E=0.05)$ (Fig. 3B). Similarly, to investigate the effects of social competition on these parameters for false recognition, we performed two separate one-

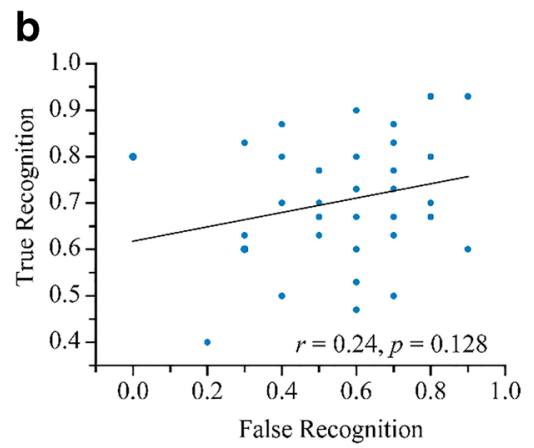

- Control - Competition

Fig. 2 Relationship between true and false recognition in the control and competition groups. There was a significant positive correlation between true and false recognition in the control group (A), but not in the competition group (B) 


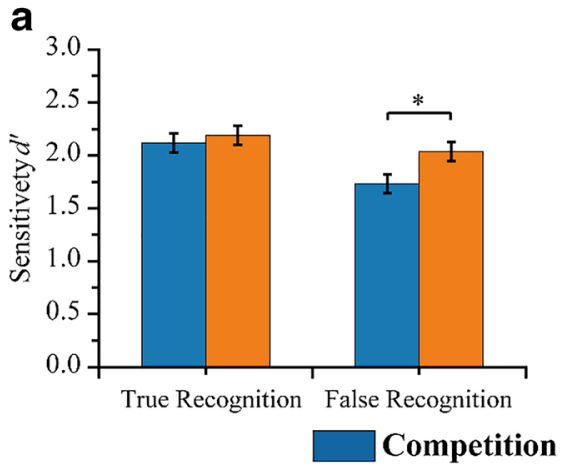

Fig. 3 The effects of social competition on memory sensitivity $\left(d^{\prime}\right)$ and response bias $(C)$ for true and false recognition. (A) Participants in the competition group (relative to the control group) showed a significantly lower $d^{\prime}$ for false recognition. (B) Participants in the competition group

way ANCOVAs with group (competition vs. control) as a between-subject factor and competitive orientation as a covariate. The ANCOVA on the $d^{\prime}$ revealed a significant main effect of group $\left(F(1,79)=5.60, p=0.020, \eta^{2}{ }_{p} 0.07\right)$. Participants in the competition group $(M=1.73, S E=0.09)$ produced a significantly lower $d^{\prime}$ than those in the control group $(M=2.04, S E=0.09)$ (Fig. 3A). Furthermore, the ANCOVA on the $C$ revealed a significant main effect of group $\left(F(1,79)=6.77, p=0.011, \eta_{p}^{2}=0.08\right)$. Participants in the competition group $(M=0.66, S E=0.07)$ showed a significantly more conservative response bias for false recognition than those in the control group $(M=0.41, S E=0.07)$ (Fig. 3B).

\section{Discussion}

To the best of our knowledge, this study is the first to explore the effect of social competition on true and false recognition using the DRM paradigm. We found that participants who performed the task within the context of social competition recognized significantly less targets and related distractors than those in the control group. Moreover, there was a positive correlation between hits for targets and false alarms for related distractors in the control group, but not in the competition group. By adopting a signal-detection approach that allows for separate measurement of memory sensitivity and response bias, we found that participants in the competition group (relative to the control group) exhibited a decreased memory sensitivity for false recognition, while those in both groups showed equivalent memory sensitivity for true recognition. Furthermore, participants in the competition group adopted a relatively more conservative response strategy for true and false recognition than those in the control group. Below, we consider the theoretical implications of these results and how they extend our understanding of the role of social influence arising in competitive contexts on memory.

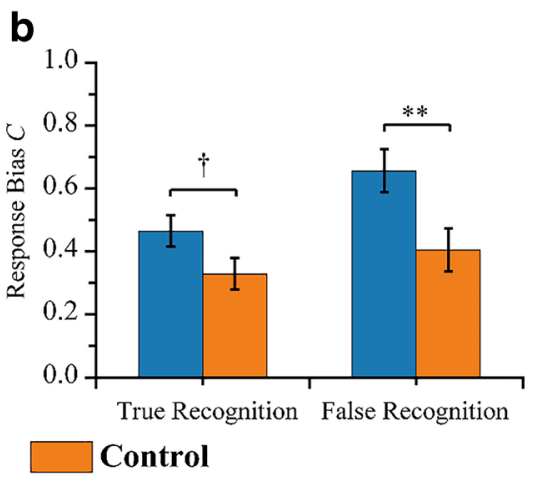

(relative to the control group) showed a marked shift towards a conservative response bias for both true and false recognition. Error bars represent standard errors of the mean. $\dagger p=0.06, * p<0.05$, ** $p$ $<0.01$

\section{Effects of social competition on false and true recognition}

Overall, the correlation analyses performed between true and false recognition seem to provide important clues about disentangling whether the activation/monitoring theory or the fuzzy trace theory provides better accounts of possible mechanisms underlying the variations in the pattern of true and false recognition performance that are linked to social competition in the present study. The results revealed a positive correlation between true and false recognition in the control group, suggesting that a common factor, namely, contextindependent semantic processing, contributes to both true and false recognition in this group, which is consistent with findings from previous studies using the DRM paradigms in noncompetitive contexts (Ballard et al., 2012; Kim \& Cabeza, 2007; Pardilla-Delgado et al., 2015; Pardilla-Delgado \& Payne, 2017b; Payne et al., 2009). As a result, the activation/monitoring theory seems to give a better account of memory processes that control true and false recognition performance in the control group because this theory assumes a relationship between true and false memories (Gallo, 2010; Roediger \& Mcdermott, 2000; Roediger et al., 2001). In contrast, we failed to find a significant correlation between them in the competition group, possibly suggesting that distinct processes, at least to some extent, may be evoked to contribute to true and false recognition during social competition. Our signal detection analysis has revealed that social competition serves to be a powerful means of enhancing item-specific processing at encoding, which in turn favors the development of memory traces for specific attributes of individual items (verbatim traces) over that of memory traces capturing the general semantic meaning of studied items, but without specific attributes (gist traces). Given that verbatim traces have been found to be especially important in challenging situations like social competition (Obidziński \& Nieznański, 2017), an enhanced verbatim-based processing would 
simultaneously reduce the accessibility of gist-based semantic traces during retrieval, resulting in a non-significant correlation between true and false recognition in the competitive context. In this sense, the fuzzy trace theory seems to provide a better account of true- and false-recognition performance in the competition group since this theory assumes some levels of independence between true and false memories (Bookbinder \& Brainerd, 2016; Brainerd, Reyna, \& Ceci, 2008a; Gallo, 2010). Taken together, these correlational results suggest different mechanisms underlying the variability of recognition memory performance for both groups. This is useful to guide our subsequent discussion on memory processes that control false- and true-recognition performance during social competition in terms of the fuzzy trace theory.

Regarding the influence of social competition on false recognition, we observed a significant reduction in participants' responding "old" to related distractors in the competition group compared to the control group. This is consistent with the prediction based on the fuzzy-trace theory (Brainerd \& Reyna, 1998; Brainerd et al., 2002; Reyna \& Brainerd, 1995). More specifically, social competition affects false recognition possibly through its modulation on how study materials are encoded, which in turn modulates false recognition. Support for this prediction comes from our observation of reduced sensitivity $\left(d^{\prime}\right)$ to related distractors by participants in the competition group compared to those in the control group. This indicates that social competition seems to encourage item-specific processing over relational processing mainly because our observation is completely in line with previous findings showing item-specific encoding effects on memory sensitivity for false recognition (Huff \& Bodner, 2013; Huff, Bodner, \& Fawcett, 2015; Mccabe, Presmanes, Robertson, \& Smith, 2004), which in turn favors the development of verbatim traces over that of gist traces at encoding. Given that itemspecific processing and relational processing work in opposition to produce false recognition (Hege \& Dodson, 2004; Roediger et al., 2001) or gist and verbatim traces work in opposition to produce false recognition (Brainerd et al., 2003; Reyna et al., 2016), an enhanced item-specific processing and the corresponding enhancement of verbatim-based processing may reduce the activation of related distractors or the accessibility of gist traces during retrieval, thereby increasing the likelihood of recollection rejection and resulting in a corresponding reduction in false recognition. In a challenging situation like social competition, a range of subjective psychological responses including negative affect states are often implicated in such a challenging situation in humans (Fletcher, Major, \& Davis, 2008; Gonzalez-Bono, Salvador, Serrano, \& Ricarte, 1999; Keikha, Yusof, \& Jourkesh, 2015; Salvador, Suay, González-Bono, \& Serrano, 2003; Zhong, Shalev, Koh, Ebstein, \& Chew, 2018). According to the affect-as-information model, affective valence influences how information is encoded (Bless et al., 1996; Clore \&
Storbeck, 2006). Negative affect encourages item-specific processing that favors the development of verbatim traces during encoding and reduces the activation of related distractors or the accessibility of gist traces during retrieval, which in turn leads to false-recognition reduction (Storbeck, 2013; Storbeck \& Clore, 2005, 2011). From this, we may make a further inference about potential mechanisms underlying the way in which social competition influences how study materials are encoded. During encoding, participants experiencing negative affect induced by social competition may guide their attention to details of study materials rather than to relational information, which reduces the activation of semantic associates or the development of gist traces and results in a corresponding reduction in false recognition, indicating the reduction in false recognition observed in the present study may partly be mediated to some degree by this affective feeling induced by social competition. Given that the fuzzy trace theory puts an emphasis on the distinction between memory processes and additional monitoring and decision processes that generally occur at retrieval, we can also speculate that at retrieval, social competition may serve to enhance retrieval monitoring and thus modulate the degree of control that participants are able to exercise over the decision criterion. Considering the cost of errors under competitive contexts, participants may adopt a more stringent response criterion as the optimal decision criterion to minimize the likelihood of false recognition. This argument is indeed supported by our findings showing that participants in the competition group set a more conservative decision criterion for judging related distractors as items that were previously seen at encoding.

In parallel, regarding effects of social competition on true recognition, participants in the competition group were less likely than those in the control group to judge a target at recognition as an item that has previously been seen at encoding. Moreover, our signal-detection analysis revealed equivalent memory sensitivity for true recognition, indicating that both groups encoded similar level of memory information about targets. This finding, in fact, provides additional evidence for our claim that social competition enhances itemspecific encoding mainly due to its consistency with previous findings showing item-specific encoding effects on memory sensitivity for true recognition (Huff \& Bodner, 2013; Huff et al., 2015; Mccabe et al., 2004). According to the fuzzy-trace theory (Brainerd \& Reyna, 1998; Brainerd et al., 2002; Reyna $\&$ Brainerd, 1995), the retrieval of both verbatim-based information (identity judgment) and gist-based information (similarity judgment) plays a role in producing true recognition. These are two types of retrieval processes involving responding to a probe that can either accurately produce retrieval of distinctive details of targets or only produce a sense of familiarity. Considering the cost of errors under competitive contexts, one can expect that the retrieval of verbatim- 
based information plays a dominant role in producing true recognition to maximize their correct responding during social competition, implying that the retrieval of target memories provides diagnostic evidence that a target was indeed studied. To achieve this, a relative tightening of the response criterion seems to be an optimal response strategy in response to targets in the context of social competition. This argument is indeed supported by our findings showing that participants in the competition group set a slightly more conservative decision criterion for judging targets as items that were previously seen at encoding. Simultaneously, a shift towards a conservative response bias for true recognition is more likely to enable participants to mistakenly judge targets as items that were not previously seen at encoding when their recognition was not accompanied by the retrieval of distinctive details or that led to retrieval of gist trace of targets, thereby leading to a corresponding true recognition reduction in the competition group. That is, when faced with an opponent, the tendency to reject targets that only produce a sense of familiarity as having been studied can potentially maximize true-recognition performance.

Finally, based on the novel findings in the present study, one may ask a fairly straightforward question: Is social competition good as it does reduce false recognition, but it also reduces overall learning in terms of true recognition? To seek possible solutions, we related our findings with previous studies on the role of social competition on memory processes. As outlined above, our signal-detection analysis revealed a nonsignificant difference in memory sensitivity for true recognition between both groups, but a marked shift towards a conservative response bias for true recognition in the competition group. The adoption of the conservative response bias for true recognition in turn increases the likelihood of mistakenly judging targets that only produce a sense of familiarity rather than clear retrieval of target memories as items that have been studied, resulting in a corresponding true recognition reduction in the competition group. These results suggest that true recognition reduction is the result of decision-based factors in the competition group. Therefore, it seems much too early to claim that social competition reduces overall learning of study materials in our study. On the other hand, two recent studies reported preliminary evidence showing that social competition reduces working memory performance (Dimenichi \& Tricomi, 2015, 2017). From this, it seems that in addition to decision-based factors, memory-based factors such as working memory that was not investigated in the present study may also play a role in true recognition reduction in the competition group. In this sense, it is tempting to speculate that social competition may reduce overall learning. However, more research is needed to deepen our understanding of this issue. Meanwhile, our study takes a further step in understanding effects of social competition on false recognition by showing reduced levels of false recognition in the competition group.
Given that participants in the competition group showed a decreased memory sensitivity for false recognition and an increased conservative response bias for false recognition, both encoding-based and decision-based factors contributed to false-recognition reduction in the competition group. These findings suggest that social competition does not merely yield negative effects on accuracy of retrieved memories, but may also serve to prevent false memories. Although these results at first may appear somewhat counterintuitive, both dark-side and bright-side effects of social competition on true and false recognition adds to a growing body of literature that social competition exerts both beneficial and detrimental effects on performance (Murayama \& Elliot, 2012; Qin, Johnson, \& Johnson, 1995; Stanne, Johnson, \& Johnson, 1999). In addition, considering that earlier studies failed to reveal impacts of social competition during both encoding and retrieval on event-based prospective memory performance (D'Angelo et al., 2012), this may indicate that variations in the pattern of memory changes that are linked to social competition depend on memory type. Such a possibility may stimulate further research on the role of social competition on other types of memory (i.e., implicit memory and autobiographical memory).

\section{Potential limitations}

Although the current study sheds new light on mechanisms underlying how true and false recognition are subject to social competition, it also has some limitations. First, the interpretation of the effects of social competition on true and false recognition is limited by the fact that memory is measured only via recognition. Thus, it will be important to explore whether these findings are generalizable to the measurement of other forms of memory, such as free recall. Second, based on an interpretation of our findings within the fuzzy-trace framework, we cannot distinguish clearly between two possible bases for the effect: (a) reduced accessibility of gist traces of related distractors and (b) strategic memory-editing processes. Furthermore, the relative contribution of different types of retrieval processes to true and false recognition during social competition is still unclear. Therefore, it might be interesting to elucidate these issues in future work. Finally, in the present study, we only focused on an important type of social competition that refers to competitive interactions between individuals. However, interpersonal competition is only one type of social competition, which includes others such as intergroup competition. This group-based competition requires both between-group competition and in-group cooperation, which has been demonstrated to play a critical role in modulating individuals' behavior (Landkammer \& Sassenberg, 2016; Tauer \& Harackiewicz, 2004; Zhu et al., 2015; Zhu et al., 2016). Given that in-group cooperation is also involved during group-based competition, the way in which group-based 
competition modulates memory processes may be more complex. As a result, it would be interesting to explore potential mechanisms underlying the role of group-based competition on true and false recognition.

\section{Conclusion}

The present study was designed to investigate how true and false recognition are subject to social influence arising in competitive contexts. We found lower levels of true and false recognition in socially competitive contexts. Such recognition responses can be attributable to the enhanced item-specific processing driven by social competition and a marked conservatism in response strategy for identifying targets and related distractors as "old." These findings should serve to stimulate further research investigating the powerful role of social competition on other aspects of memory processes.

Acknowledgements This work was supported by the National Natural Science Foundation of China (Grant Number 31600929), the Fundamental Research Funds for the Central Universities (Grant Number 010914380002) and a grant from Society for Social Psychology of Jiangsu Province (Grant Number 20SSXGH006).

Author contributions ZL and YL contributed to the study concept and design. Testing and data collection were performed by ZL. ZL and TL performed the data analysis under the supervision of YL. ZL drafted the manuscript. YL provided critical revisions and the final version of the manuscript for submission. All authors approved the final version of the manuscript for submission. We would like to thank Dr. David O'Connor for his diligent proofreading of this manuscript.

\section{Compliance with ethical standards}

Conflicts of interest The authors have no conflicts of interest to declare.

Open Practices Statements The data and materials for the present experiment are available upon reasonable request and this experiment was not preregistered.

\section{References}

Anderson, J. R. (1972). Fran: A simulation model of free recall. Psychology of Learning and Motivation, 5, 315-378. https://doi. org/10.1016/S0079-7421(08)60444-2

Arndt, J., \& Reder, L. M. (2003). The effect of distinctive visual information on false recognition. Journal of Memory and Language, 48(1), 1-15. https://doi.org/10.1016/S0749-596X(02)00518-1

Balas, B., \& Thomas, L. E. (2015). Competition makes observers remember faces as more aggressive. Journal of Experimental Psychology: General, 144(4), 711-716. https://doi.org/10.1037/xge0000078

Ballard, M. E., Gallo, D. A., \& Wit, H. D. (2012). Psychoactive drugs and false memory: Comparison of dextroamphetamine and delta-9tetrahydrocannabinol on false recognition. Psychopharmacology, 219(1), 15-24. https://doi.org/10.1007/s00213-011-2374-5

Barnier, A. J., Sutton, J., Harris, C. B., \& Wilson, R. A. (2008). A conceptual and empirical framework for the social distribution of cognition: The case of memory. Cognitive Systems Research, 9(1), 33-51. https://doi.org/10.1016/j.cogsys.2007.07.002

Benjamin, A. S. (2007). Memory is more than just remembering: Strategic control of encoding, accessing memory, and making decisions. Psychology of Learning and Motivation, 48(12), 175-223. https://doi.org/10.1016/S0079-7421(07)48005-7

Blair, I. V., Lenton, A. P., \& Hastie, R. (2002). The reliability of the DRM paradigm as a measure of individual differences in false memories. Psychonomic Bulletin \& Review, 9(3), 590-596. https://doi.org/10. 3758/BF03196317

Bless, H., Schwarz, N., Clore, G. L., Golisano, V., Rabe, C., \& Wölk, M. (1996). Mood and the use of scripts: does a happy mood really lead to mindlessness? Journal of Personality and Social Psychology, 71(4), 665-679. https://doi.org/10.1037/0022-3514.71.4.665

Bless, H., Strack, F., \& Walther, E. (2001). Memory as a target of social influence?: Memory distortions as a function of social influence and metacognitive knowledge. In J. P. Forgas \& K. D. Williams (Eds.), The Sydney symposium of social psychology. Social influence: Direct and indirect processes (pp. 167-183). New York, NY, US: Psychology Press.

Bookbinder, S. H., \& Brainerd, C. J. (2016). Emotion and false Memory: The context-content paradox. Psychological Bulletin, 142(12), 1315-1351. https://doi.org/10.1037/bul0000077

Brainerd, C. J., \& Reyna, V. F. (1998). Fuzzy-trace theory and children's false memories. Journal of Experimental Child Psychology, 71(2), 81-129. https://doi.org/10.1006/jecp.1998.2464

Brainerd, C. J., \& Reyna, V. F. (2005). The science of false memory. New York, NY: Oxford University Press.

Brainerd, C. J., Reyna, V. F., \& Ceci, S. J. (2008a). Developmental reversals in false memory: A review of data and theory. Psychological Bulletin, 134(3), 343-382. https://doi.org/10.1037/ 0033-2909.134.3.343

Brainerd, C. J., Reyna, V. F., Ron, W., \& Mojardin, A. H. (2003). Recollection rejection: False-memory editing in children and adults. Psychological Review, 110(4), 762-784. https://doi.org/10.1037/ 0033-295X.110.4.762

Brainerd, C. J., Stein, L. M., Silveira, R. A., Rohenkohl, G., \& Reyna, V. F. (2008b). How does negative emotion cause false memories? Psychological Science, 19(9), 919-925. https://doi.org/10.1111/j. 1467-9280.2008.02177.x

Brainerd, C. J., Wright, R., Reyna, V. F., \& Payne, D. G. (2002). DualRetrieval Processes in Free and Associative Recall. Journal of Memory and Language, 46(1), 120-152. https://doi.org/10.1006/ jmla.2001.2796

Carmichael, A. M., \& Gutchess, A. H. (2016). Using warnings to reduce categorical false memories in younger and older adults. Memory, 24(6), 853-863. https://doi.org/10.1080/09658211.2015.1059454

Casto, K. V., \& Edwards, D. A. (2016). Before, during, and after: How phases of competition differentially affect testosterone, cortisol, and estradiol levels in women athletes. Adaptive Human Behavior \& Physiology, 2(1), 11-25. https://doi.org/10.1007/s40750-015-00282

Chen, X., Xie, X., \& Chang, S. (2011). Cooperative and competitive orientation among Chinese people: Scale development and validation. Management and Organization Review, 7(2), 353-379. https:// doi.org/10.1111/j.1740-8784.2011.00215.x

Clore, G. L., \& Storbeck, J. (2006). Affect as information about liking, efficacy, and importance. In J. P. Forgas (Ed.), Affect in social thinking and behavior (pp. 123-141): Psychology Press.

Cohen, J. (1988). Statistical power analysis for the behavioral sciences (2nd). Hillsdale, NJ: Erlbaum.

Cohen, J. (1992). A power primer. Psychological Bulletin, 112(1), 155159. https://doi.org/10.1037/0033-2909.112.1.155

Curran, T., Debuse, C., \& Leynes, P. A. (2007). Conflict and criterion setting in recognition memory. Journal of Experimental 
Psychology: Learning, Memory, and Cognition, 33(1), 2-17. https:// doi.org/10.1037/0278-7393.33.1.2

D'Angelo, G., Bosco, A., Bianco, C., \& Brandimonte, A. (2012). The effects of collaboration and competition on pro-social prospective memory. Psychologica Belgica, 52(2-3), 205-228. https://doi.org/ $10.5334 / \mathrm{pb}-52-2-3-205$

Deese, J. (1959). On the prediction of occurrence of particular verbal intrusions in immediate recall. Journal of Experimental Psychology, 58, 17-22. https://doi.org/10.1037/h0046671

Deutsch, M. (1949). A theory of cooperation and competition. Human Relations, 2(2), 129-152. https://doi.org/10.1007/BF00116765

Diekelmann, S., Wilhelm, I., Wagner, U., \& Born, J. (2011). Elevated cortisol at retrieval suppresses false memories in parallel with correct memories. Journal of Cognitive Neuroscience, 23(4), 772-781. https://doi.org/10.1162/jocn.2010.21493

Dimenichi, B. C., \& Tricomi, E. (2015). The power of competition: Effects of social motivation on attention, sustained physical effort, and learning. Frontiers in Psychology, 6, 1282. https://doi.org/10. 3389/fpsyg.2015.01282

Dimenichi, B. C., \& Tricomi, E. (2017). Increases in brain activity during social competition predict decreases in working memory performance and later recall. Human Brain Mapping, 38(1), 457-471. https://doi.org/10.1002/hbm.23396

Echterhoff, G., \& Hirst, W. (2009). Social influence on memory. Social Psychology, 40(3), 106-110. https://doi.org/10.1027/1864-9335.40. 3.106

Faul, F., Erdfelder, E., Lang, A. G., \& Buchner, A. (2007). G*Power 3: A flexible statistical power analysis program for the social, behavioral, and biomedical sciences. Behavior Research Methods, 39(2), 175191. https://doi.org/10.3758/BF03193146

Fletcher, T. D., Major, D. A., \& Davis, D. D. (2008). The interactive relationship of competitive climate and trait competitiveness with workplace attitudes, stress, and performance. Journal of Organizational Behavior, 29(7), 899-922. https://doi.org/10.2307/ 30163356

Forgas, J. P., Laham, S. M., \& Vargas, P. T. (2015). Mood effects on eyewitness memory: Affective influences on susceptibility to misinformation. Journal of Experimental Social Psychology, 41(6), 574-588. https://doi.org/10.1016/j.jesp.2004.11.005

Gallo, D. A. (2010). False memories and fantastic beliefs: 15 years of the DRM illusion. Memory \& Cognition, 38(7), 833-848. https://doi. org/10.3758/mc.38.7.833

Gallo, D. A. (2013). Retrieval expectations affect false recollection: Insights from a criterial recollection task. Current Directions in Psychological Science, 22(4), 316-323. https://doi.org/10.1177/ 0963721413481472

Gallo, D. A., Roberts, M. J., \& Seamon, J. G. (1997). Remembering words not presented in lists: Can we avoid creating false memories? Psychonomic Bulletin \& Review, 4(2), 271-276. https://doi.org/10. 3758/BF03209405

Gonzalez-Bono, E., Salvador, A., Serrano, M. A., \& Ricarte, J. (1999). Testosterone, cortisol, and mood in a sports team competition. Hormones and Behavior, 35(1), 55-62. https://doi.org/10.1006/ hbeh.1998.1496

Hege, A. C., \& Dodson, C. S. (2004). Why distinctive information reduces false memories: Evidence for both impoverished relationalencoding and distinctiveness heuristic accounts. Journal of Experimental Psychology: Learning, Memory, and Cognition, 30(4), 787. https://doi.org/10.1037/0278-7393.30.4.787

Hidi, S., \& Renninger, K. A. (2006). The four-phase model of interest development. Educational Psychologist, 41(2), 111-127. https://doi. org/10.1207/s15326985ep4102_4

Hu, X., \& Xie, X. (2012). Validation of the domain-specific risk-taking scale in Chinese college students. Judgment and Decision making, 7(2), 181-188. https://doi.org/10.1093/geronb/gbr156
Huff, M. J., \& Bodner, G. E. (2013). When does memory monitoring succeed versus fail? comparing item-specific and relational encoding in the drm paradigm. Journal of Experimental Psychology: Learning, Memory, and Cognition, 39(4), 1246-1256. https://doi.org/10.1037/a0031338

Huff, M. J., Bodner, G. E., \& Fawcett, J. M. (2015). Effects of distinctive encoding on correct and false memory: A meta-analytic review of costs and benefits and their origins in the drm paradigm. Psychonomic Bulletin \& Review, 22(2), 349-365. https://doi.org/ 10.3758/s13423-014-0648-8

Hunt, R. R., \& Einstein, G. O. (1981). Relational and item-specific information in memory. Journal of Verbal Learning and Verbal Behavior, 20(5), 497-514. https://doi.org/10.1016/S0022-5371(81) 90138-9

Hunt, R. R., \& Mcdaniel, M. A. (1993). The enigma of organization and distinctiveness. Journal of Memory and Language, 32(4), 421-445. https://doi.org/10.1006/jmla.1993.1023

Johnson, D. W., \& Johnson, R. T. (1989). Cooperation and competition: Theory and research. Edina, MN: Interaction Book.

Kapucu, A., Rotello, C. M., Ready, R. E., \& Seidl, K. N. (2008), Response bias in "remembering" emotional stimuli: A new perspective on age differences. Journal of Experimental Psychology. Learning, Memory, and Cognition, 34(3), 703-711. https://doi.org/ 10.1037/0278-7393.34.3.703

Keikha, B. M., Yusof, S. M., \& Jourkesh, M. (2015). The relationship between pre-competition state anxiety components and mood state sub-scales scores and the result of among college athletes through temporal patterning. International Journal of Sports Science, 5(1), 8-15. https://doi.org/10.5923/j.sports.20150501.02

Kim, H., \& Cabeza, R. (2007). Differential contributions of prefrontal, medial temporal, and sensory-perceptual regions to true and false memory formation. Cerebral Cortex, 17(9), 2143-2150. https://doi. org/10.1093/cercor/bhl122

Landkammer, F., \& Sassenberg, K. (2016). Competing while cooperating with the same others: The consequences of conflicting demands in co-opetition. Journal of Experimental Psychology: General, 145(12), 1670-1686. https://doi.org/10.1037/xge0000232

Loftus, E. F., \& Pickrell, J. E. (1995). The formation of false memories. Psychiatric Annals, 25(12), 720-725. https://doi.org/10.3928/00485713-19951201-07

Mccabe, D. P., Presmanes, A. G., Robertson, C. L., \& Smith, A. D. (2004). Item-specific processing reduces false memories. Psychonomic Bulletin \& Review, 11(6), 1074-1079. https://doi.org/ 10.3758/BF03196739

Mccabe, D. P., \& Smith, A. D. (2002). The effect of warnings on false memories in young and older adults. Memory \& Cognition, 30(7), 1065-1077. https://doi.org/10.3758/bf03194324

Mcdermott, K. B., \& Roediger, H. L. I. (1998). Attempting to avoid illusory memories: Robust false recognition of associates persists under conditions of explicit warnings and immediate testing. Journal of Memory and Language, 39(3), 508-520. https://doi.org/ 10.1006/jmla.1998.2582

Murayama, K., \& Elliot, A. J. (2012). The competition-performance relation: A meta-analytic review and test of the opposing processes model of competition and performance. Psychological Bulletin, 138(6), 1035-1070. https://doi.org/10.1037/a0028324

Newbury, C., \& Monaghan, P. (2019). When does sleep affect veridical and false memory consolidation? A meta-analysis. Psychonomic Bulletin and Review, 26, 387-400. https://doi.org/10.3758/s13423018-1528-4

Ngaosuvan, L., \& Mäntylä, T. (2010). Rewarded remembering: Dissociations between self-rated motivation and memory performance. Scandinavian Journal of Psychology, 46(4), 323-330. https://doi.org/10.1111/j.1467-9450.2005.00462.x

Nielson, K. A., \& Correro, A. N. (2017). Post-learning arousal enhances veridical memory and reduces false memory in the Deese-Roediger- 
McDermott paradigm. Neurobiology of Learning and Memory, 144, 198-207. https://doi.org/10.1016/j.nlm.2017.07.009

Nitschke, J. P., Chu, S., Pruessner, J. C., Bartz, J. A., \& Sheldon, S. (2019). Post-learning stress reduces the misinformation effect: Effects of psychosocial stress on memory updating. Psychoneuroendocrinology, 102, 164-171. https://doi.org/10.1016/ j.psyneuen.2018.12.008

Obidziński, M., \& Nieznański, M. (2017). False memory for orthographically versus semantically similar words in adolescents with dyslexia: A fuzzy-trace theory perspective. Annals of Dyslexia, 67(3), 318332. https://doi.org/10.1007/s11881-017-0146-6

Paige, L. E., Amado, S., \& Gutchess, A. H. (2017). Influence of encoding instructions and response bias on cross-cultural differences in specific recognition. Culture \& Brain, 5(4), 153-168. https://doi.org/10. 1007/s40167-017-0055-x

Pardilla-Delgado, E., Alger, S. E., Cunningham, T. J., Kinealy, B., \& Payne, J. D. (2015). Effects of post-encoding stress on performance in the DRM false memory paradigm. Learning \& Memory, 23(1), 46-50. https://doi.org/10.1101/lm.039354.115

Pardilla-Delgado, E., \& Payne, J. D. (2017a). The Deese-RoedigerMcDermott (DRM) task: A simple cognitive paradigm to investigate false memories in the laboratory. Journal of Visualized Experiments, 119, e54793. https://doi.org/10.3791/54793

Pardilla-Delgado, E., \& Payne, J. D. (2017b). The impact of sleep on true and false memory across long delays. Neurobiology of Learning and Memory, 137, 123-133. https://doi.org/10.1016/j.nlm.2016.11.016

Payne, J. D., Schacter, D. L., Propper, R. E., Huang, L. W., \& Stickgold, R. (2009). The role of sleep in false memory formation. Neurobiology of Learning and Memory, 92(3), 327-334. https:// doi.org/10.1016/j.nlm.2009.03.007

Pesta, B. J., Murphy, M. D., \& Sanders, R. E. (2001). Are emotionally charged lures immune to false memory? Journal of Experimental Psychology: Learning, Memory, and Cognition, 27(2), 328-338. https://doi.org/10.1037/0278-7393.27.2.328

Plass, J. L., O'Keefe, P. A., Homer, B. D., Case, J., Hayward, E. O., Stein, M., \& Perlin, K. (2013). The impact of individual, competitive, and collaborative mathematics game play on learning, performance, and motivation. Journal of Educational Psychology, 105(4), 1050-1066. https://doi.org/10.1037/a0032688

Qin, Z., Johnson, D. W., \& Johnson, R. T. (1995). Cooperative versus competitive efforts and problem solving. Review of Educational Research, 65(2), 129-143. https://doi.org/10.3102/ 00346543065002129

Rajaram, S., \& Pereira-Pasarin, L. P. (2007). Collaboration can improve individual recognition memory: Evidence from immediate and delayed tests. Psychonomic Bulletin \& Review, 14(1), 95-100. https:// doi.org/10.3758/BF03194034

Reyna, V. F., \& Brainerd, C. J. (1995). Fuzzy-trace theory: An interim synthesis. Learning and Individual Differences, 7(1), 1-75. https:// doi.org/10.1016/1041-6080(95)90031-4

Reyna, V. F., Corbin, J. C., Weldon, R. B., \& Brainerd, C. J. (2016). How fuzzy-trace theory predicts true and false memories for words, sentences, and narratives. Journal of Applied Research in Memory and Cognition, 5(1), 1-9. https://doi.org/10.1016/j.jarmac.2015.12. 003

Reysen, M. B. (2007). The effects of social pressure on false memories. Memory \& Cognition, 35(1), 59-65. https://doi.org/10.3758/ BF03195942

Roediger, H. L. I., \& McDermott, K. B. (1995). Creating false memories: Remembering words not presented in lists. Journal of Experimental Psychology: Learning, Memory, and Cognition, 21(4), 803-814. https://doi.org/10.1037/0278-7393.21.4.803

Roediger, H. L. I., \& Mcdermott, K. B. (1996). False perceptions of false memories. Journal of Experimental Psychology: Learning, Memory, and Cognition, 22(3), 814-816.
Roediger, H. L. I., \& Mcdermott, K. B. (2000). Tricks of memory. Current Directions in Psychological Science, 9(4), 123-127. https://doi.org/10.1111/1467-8721.00075

Roediger, H. L. I., Watson, J. M., Mcdermott, K. B., \& Gallo, D. A. (2001). Factors that determine false recall: A multiple regression analysis. Psychonomic Bulletin \& Review, 8(3), 385-407. https:// doi.org/10.3758/BF03196177

Salvador, A., Suay, F., González-Bono, E., \& Serrano, M. A. (2003). Anticipatory cortisol, testosterone and psychological responses to judo competition in young men. Psychoneuroendocrinology, 28(3), 364-375. https://doi.org/10.1016/s0306-4530(02)00028-8

Schacter, D. L., Guerin, S. A., \& Jacques, P. L. S. (2011). Memory distortion: An adaptive perspective. Trends in Cognitive Sciences, 15(10), 467-474. https://doi.org/10.1016/j.tics.2011.08.004

Seamon, J. G., Lee, I. A., Toner, S. K., Wheeler, R. H., Goodkind, M. S., \& Birch, A. D. (2002a). Thinking of critical words during study Is unnecessary for false memory in the Deese, Roediger, and Mcdermott procedure. Psychological Science, 13(6), 526-531. https://doi.org/10.1111/1467-9280.00492

Seamon, J. G., Luo, C. R., Kopecky, J. J., Price, C. A., Leeatt, R., Fung, N. S., \& Schwartz, M. A. (2002b). Are false memories more difficult to forget than accurate memories? The effect of retention interval on recall and recognition. Memory \& Cognition, 30(7), 1054-1064. https://doi.org/10.3758/BF03194323

Smeets, T., Otgaar, H., Candel, I., \& Wolf, O. T. (2008). True or false? Memory is differentially affected by stress-induced cortisol elevations and sympathetic activity at consolidation and retrieval. Psychoneuroendocrinology, 33(10), 1378-1386. https://doi.org/10. 1016/j.psyneuen.2008.07.009

Stadler, M. A., Roediger, H. L., \& Mcdermott, K. B. (1999). Norms for word lists that create false memories. Memory \& Cognition, 27(3), 494-500. https://doi.org/10.3758/BF03211543

Stanne, M. B., Johnson, D. W., \& Johnson, R. T. (1999). Does competition enhance or inhibit motor performance: A meta-analysis. Psychological Bulletin, 125(1), 133-154. https://doi.org/10.1037/ 0033-2909.125.1.133

Storbeck, J. (2013). Negative affect promotes encoding of and memory for details at the expense of the gist: Affect, encoding, and false memories. Memory \& Cognition, 27(5), 800-819. https://doi.org/ 10.1080/02699931.2012.741060

Storbeck, J., \& Clore, G. L. (2005). With sadness comes accuracy; with happiness, false memory: Mood and the false memory effect. Psychological Science, 16(10), 785-791. https://doi.org/10.2307/ 40064315

Storbeck, J., \& Clore, G. L. (2011). Affect influences false memories at encoding: Evidence from recognition data. Emotion, 11(4), 981989. https://doi.org/10.1037/a0022754

Straube, B., Green, A., Chatterjee, A., \& Kircher, T. (2011). Encoding social interactions: The neural correlates of true and false memories. Journal of Cognitive Neuroscience 23(2), 306-324. https://doi.org/ 10.1162/jocn.2010.21505

Tauer, J. M., \& Harackiewicz, J. M. (2004). The effects of cooperation and competition on intrinsic motivation and performance. Journal of Personality and Social Psychology, 86(6), 849-861. https://doi.org/ 10.1037/0022-3514.86.6.849

Verde, M. F., \& Rotello, C. M. (2007). Memory strength and the decision process in recognition memory. Memory \& Cognition, 35(2), 254262. https://doi.org/10.3758/bf03193446

Watson, J. M., Mcdermott, K. B., \& Balota, D. A. (2004). Attempting to avoid false memories in the Deese/Roediger-McDermott paradigm: Assessing the combined influence of practice and warnings in young and old adults. Memory \& Cognition, 32(1), 135-141. https://doi.org/10.3758/BF03195826

Weldon, M. S. (2000). Remembering as a social process. Psychology of Learning and Motivation, 40(1), 67-120. https://doi.org/10.1016/ S0079-7421(00)80018-3 
Weldon, M. S., \& Bellinger, K. D. (1997). Collective memory: Collaborative and individual processes in remembering. Journal of Experimental Psychology: Learning, Memory, and Cognition, 23(5), 1160-1175. https://doi.org/10.1037/0278-7393.23.5.1160

Wyer, R. S., \& Srull, T. K. (1986). Human cognition in its social context. Psychological Review, 93(3), 322-359. https://doi.org/10.1037/ 0033-295X.93.3.322

Zaragoza, M. S., Payment, K. E., Ackil, J. K., Drivdahl, S. B., \& Beck, M. (2001). Interviewing witnesses: Forced confabulation and confirmatory feedback increase false memories. Psychological Science, 12(6), 473-477. https://doi.org/10.1111/1467-9280.00388

Zheng, Z., Lang, M., Wang, W., Xiao, F., \& Li, J. (2018). Electrophysiological evidence for the effects of emotional content on false recognition memory. Cognition, 179, 298-310. https://doi. org/10.1016/j.cognition.2018.06.013

Zhong, S., Shalev, I., Koh, D., Ebstein, R. P., \& Chew, S. H. (2018). Competitiveness and stress. International Economic Review, 59(3), 1263-1281. https://doi.org/10.2139/ssrn.2717459
Zhu, Y., Guan, X., \& Li, Y. (2015). The effects of intergroup competition on prosocial behaviors in young children: A comparison of 2.5-3.5 year-olds with 5.5-6.5 year-olds. Frontiers in Behavioral Neuroscience, 9, 16. https://doi.org/10.3389/fnbeh.2015.00016

Zhu, Y., Wang, J., Lv, X., \& Li, Y. (2016). Once failed, twice shy: How group-based competition influences risk preference in young children. Journal of Experimental Psychology: General, 145(4), $397-$ 401. https://doi.org/10.1037/xge0000156

Zoladz, P. R., Peters, D. M., Kalchik, A. E., Hoffman, M. M., Aufdenkampe, R. L., Woelke, S. A., ... Talbot, J. N. (2014). Brief, pre-learning stress reduces false memory production and enhances true memory selectively in females. Physiology \& Behavior, 128(3), 270-276. https://doi.org/10.1016/j.physbeh.2014.02.028

Publisher's note Springer Nature remains neutral with regard to jurisdictional claims in published maps and institutional affiliations. 